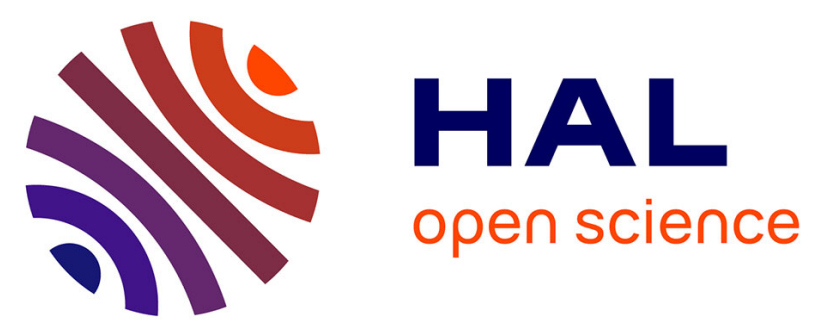

\title{
Development of Product Engineering Skills with PLM Applications Through Collaborative Educational Projects
}

Carlos Vila, Rafael Torres, Santiago C. Gutiérrez, Amparo Meseguer

\section{To cite this version:}

Carlos Vila, Rafael Torres, Santiago C. Gutiérrez, Amparo Meseguer. Development of Product Engineering Skills with PLM Applications Through Collaborative Educational Projects. 15th IFIP International Conference on Product Lifecycle Management (PLM), Jul 2018, Turin, Italy. pp.338-347, 10.1007/978-3-030-01614-2_31. hal-02075566

\section{HAL Id: hal-02075566 https://hal.inria.fr/hal-02075566}

Submitted on 21 Mar 2019

HAL is a multi-disciplinary open access archive for the deposit and dissemination of scientific research documents, whether they are published or not. The documents may come from teaching and research institutions in France or abroad, or from public or private research centers.
L'archive ouverte pluridisciplinaire HAL, est destinée au dépôt et à la diffusion de documents scientifiques de niveau recherche, publiés ou non, émanant des établissements d'enseignement et de recherche français ou étrangers, des laboratoires publics ou privés.

\section{(c)(1)}

Distributed under a Creative Commons Attribution| 4.0 International License 


\title{
Development of Product Engineering skills with PLM applications through Collaborative Educational Projects
}

\author{
Carlos Vila ${ }^{1[0000-0003-1655-9418]}$, Rafael Torres ${ }^{1}$, Santiago C. Gutiérrez ${ }^{1}$ and Amparo Me- \\ seguer $^{1}$ \\ ${ }^{1}$ Universitat Politècnica de València, Camino de Vera s/n, 46022, Valencia, SPAIN \\ carvipas@upv.es
}

\begin{abstract}
In the industrial discipline of product design and manufacturing, training and learning methods for last academic course engineering students is difficult and complex since they have to integrate technical knowledge with computer-aided applications (CAx) and new skills in collaborative work. With the trends of Industry 4.0, companies request new talents and improved competences from the very first time. The fact that Product Lifecycle Management (PLM) platforms with a huge variety of tools support structured collaborative practices drives us to use them as a gear to integrate all the engineering and put it into practice for engineering content creation. In this contribution we present an innovative academic project for the last academic course students integrating several subjects in order to develop an industrial project working in a PLM platform. The platform allows us to control not only the data but also the scheduled activities of a project while the participants use different engineering applications in each phase of the project. Traditionally, engineering education deals with the learning of CAD, CAE and CAM tools separately, giving a partial learning experience and vision to the students. This communication presents a structured integrated vision of this learning project and the achieved results.
\end{abstract}

Keywords: Project Based Learning, Collaborative Engineering, Design for Manufacturing, Industry 4.0 skills, PLM implementation.

\section{Introduction}

Manufacturing companies are in continuous product lifecycle improvement. From the perspective of manufacturing, emerging technologies such additive manufacturing, hydroforming and composites molding, can help in obtaining more quality parts and products. However, previous activities to manufacturing, particularly design and development, are difficult to improve since they need not only the latest information and communication technologies but also cultural changes.

Since early nineties new work philosophies such as Concurrent Engineering (CE), Collaborative Engineering (CoE), or Integrated Product, Processes and Resources Development (IPPRD) have been topics of interest. Conversely, many corporations find very complicated to implement this cooperative way of working and, at the same time, updated groupware. 
This major change of implementing virtual and collaborative environments represents not only a great investment but also a great effort in terms of time and team training. From this perspective, there is a claim from the industry that engineering formation must incorporate these new skills [1].

In this contribution, we will present the current situation for the companies and the implementation of some 4.0 Industry enablers and the collaborative engineering pilot project for academia that we are developing.

This communication has the following structure: section 2 provides a review of computer support for collaborative practices, section 3 explain the proposed method, section 4 the experimental procedure, section 5 the results discussion and section 6 shows the conclusions and future work.

\section{Issues in Computer Support for Collaborative Work}

Engineers from design and manufacturing disciplines, and Academic Researchers, view Collaborative Engineering as a key issue for reducing working time of product lifecycle stages and achieving product quality and reliability. The accomplishment of Collaborative Engineering within any organization is based on the premise of how prepared are the different working team actors for collaboration among the different working teams involved in the different product life cycle stages [2].

In that way, we must give to the working teams the tools for an effective communication and collaboration to ease the sharing of data and information related to product design, manufacturing process planning and product industrialization. It is important to highlight that Computer Support for Collaborative Work (CSCW) discipline includes many perspectives to achieve the integration of tools, methodologies and people.

There are different definitions of CSCW, depending on the nature of the application. CSCW is primarily concerned to people and computers. It is an environment where computers provide support to a group of people to accomplish a common goal or task. More concisely, CSCW is a "set of software, hardware, language components and procedures that support a group of people in a decision related meeting”.

The type of CSCW environment is, basically, determined by time and place dimensions. The different types of interactions based on these two dimensions can be the combination of different scenarios. On one hand, working sessions at the same time (synchronous) or at different time (asynchronous). On the other hand, working meetings in the same place (face to face) or in geographically dispersed locations (distributed).

From the CSCW perspective, there are four main areas for training engineers in collaborative skills: Organizational, Sociological, Psychological and Technological [3]. Organizational training deals with how to structure data, information and knowledge, how to control the access and how to use and to distribute it, as well as project management. Sociological training is focused on how to manage groups and the way they work in new environments. Psychological training tries to empower the behavior of individual people not only in real but in virtual teams. Finally, technological training can be the easiest one since it is about empower the use of computer applications. 
If we structure and balance the learning process, team collaboration can be potentially enhance and the productivity and effectiveness of the engineering group will be a real fact according to concurrent engineering principles. In order to support collaboration we can use methodologies and tools but they should come with metrics and incentives system.

With this structured vision, we can address the main issues to handle and the skills to improve for engineers working in collaborative environments (Fig. 1).

\section{Academic Skills for Product Design in Industry 4.0}

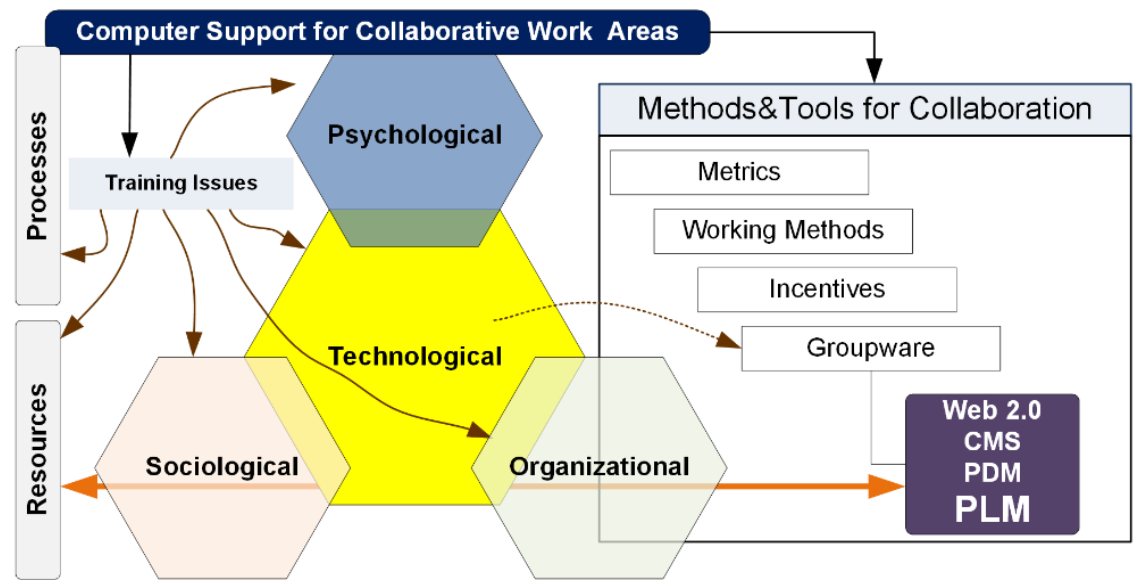

Fig. 1. CSCW Issues, Methods and Tools.

Computer tools for collaboration are defined as Groupware and a PLM system can be qualified as the most complete one, due to many of its capabilities. For example, the emergence and widespread use of web 2.0 offers an incredible potential for information sharing among geographically distributed people in different locations that work at different timetable [4]. However, they do not provide support for structured collaboration and information sharing including data management access control and project schedule.

Therefore, it is important in this context to focus the characteristics of a groupware if we are planning to implement and train engineering teams in collaborative development processes.

\subsection{Groupware Features}

An important point about Groupware is to detect the different functionalities that it can have. Moreover, we need to understand how the software will support procedures, methods and applications for the activities of the working groups. For instance, a functionality or feature for the early stage activities is how it can manage the brainstorming during the initial process to generate ideas, structure them and evaluate them. 
Another desired feature could be how the software manage collaborative part/product designs and if it facilitates revisions over the web. According to this reasoning, basic features that we should look for are:

- Interaction facilities for synchronous or asynchronous meetings.

- Coordination of performed tasks among team members.

- Distribution of data when needed through web platforms.

- Visualization and access to data according to roles and workflows.

- Data hiding, separating public and private data.

- Sharing of data, engineering drawings, applications, and so on among participants.

These features are crucial for Collaborative Engineering but, although they are aligned with industry 4.0 principles, this technology does not guarantee a successful implementation of collaborative environments [5]. These features together provide a complete architecture to support engineering activities and decision-making process. It is what we will call Product Lifecycle Management (PLM) system. However, it is needed a formation in the tools and in methods that support this new way of working within environments full of data and information.

\subsection{Team formation for Collaborative Engineering}

Engineering working teams or multidisciplinary teams that work under the umbrella of industry 4.0 will have to use these groupware applications. The problem is that, up to now, engineering students have not had an integrated formation putting together all the technical knowledge and information and communication technology [6]. The main reasons why academic organizations does not have incorporated this way of formation is complex but we summarize them as follows:

- Regular Academic are based on isolated subjects.

- Vertical integration and planning is sometimes difficult although it is supposed that some subjects are required prior to others.

- Horizontal integration is complicated since academic staff does not want to be integrated in a global academic project.

- It requires a great effort to put together some multiple points of view, perspectives and expertise in a common project with a practical objective.

- It requires extra work to define the academic project and the metrics.

- Finally, to communicate and train in all the skills and best practices to the students and, at the same time, summarize all the features of the collaboration.

The efficient use of PLM tools goes beyond simply purchasing the platform and its applications. Particularly, these platforms, demands a deep knowledge on how to use it effectively to support team members' interactions while working with advanced authoring applications [7]. Therefore, it is a key issue to define a correct implementation and customized training scenario [8].

The nonexistence of an integrated perspective in the engineering curriculum overlooks the necessity of teaching valuable skills in the areas of: project and workgroup 
management in cross-functional distributed teams, identification and resolution of design and manufacturing problems, efficient collaboration and workflow management.

The academia is working to overcome these curriculum limitations and some works claim for more initiatives to broaden vision of the professional activities in engineering [9], however, this ongoing process still requires many issues to be improved.

\section{$3 \quad$ Methodology}

\subsection{PLM performances approach}

In order to draw a rational curriculum, we have done a deep analysis of this new way of working with PLM platforms. For the experimental procedure, we have grouped performances of these platforms and, then, we have tried to use most of the performances in the regular academic engineering course. For this work, and based on previous works [10], several main categories have been defined and, within each one of them, we have identified functionalities or applications that should be included for engineering tasks (Table 1).

Table 1. PLM tool grouped performances and functionalities

\begin{tabular}{ll}
\hline Category & \multicolumn{1}{c}{ Description and Functionalities } \\
\hline Personal data & $\begin{array}{l}\text { Professional data for inside and outside of the organization and } \\
\text { meeting tools. Contact list/manager, Group Calendar }\end{array}$ \\
\hline Social & Communication tools and exchanging of data, information and \\
& ideas. There are many of them free, the problem is to synchronise \\
& them with the process. e-mail- News group - Web Conferencing - \\
& Instant Messaging / Chat, Audio Conferencing, Whiteboard \\
\hline Application & Applications related with Modelling, assembly simulation, virtual \\
& manufacturing and many other needed for the product design and \\
& development CAD/CAE/CAM. Modelling, simulation, Machin- \\
& ing. \\
\hline Data Management & $\begin{array}{l}\text { Applications related with CAx data and other electronic docu- } \\
\text { ments. File sharing-management, Version Control, Search Sys- } \\
\text { tem, Ole Based Access Control, Access Control/Security }\end{array}$ \\
\hline Decision Support & $\begin{array}{l}\text { Applications for interaction between the members of the team, } \\
\text { synchronous or asynchronous, and decision-making. Discussion } \\
\text { Forum/group, Voting system, Survey and Feedback. }\end{array}$ \\
\hline Project Management & $\begin{array}{l}\text { Collaborative process need tools for planning and resources as- } \\
\text { signment. Theses apps must enable the project time scheduling } \\
\text { and tasks coordination. Project planning, Workflow, Tasks Re- } \\
\text { minder, New events e-mail notification. }\end{array}$ \\
\hline Miscellaneous & $\begin{array}{l}\text { Includes different applications that could be used during the col- } \\
\text { laboration. All of them are based on web 2.0 similar to social net- } \\
\text { works. Reporting, Time card system, Integration with other sys- } \\
\text { tem, Personalised profile. }\end{array}$ \\
\hline
\end{tabular}


The table briefly shows the set of functionalities included within each of the main categories. Such functionalities list has helped to characterize a PLM platform and match a particular application for developing skills in concurrent engineering environments. According to the project objectives and planning, the initial formation can be customized and limited just to the needed tools or applications among all of the selected PLM platform.

\subsection{Collaborative training for enhance Product Design skills in Industry 4.0}

PLM systems provide a technological framework, where the interactions among participants can be scheduled and documented, but collaboration processes must be defined and documented to recreate real processes and to train engineers, and those aspects are still very limited. Project-Based Learning (PBL) can be seen as a way to recreate a limited and simple product design and engineering context, where students must collaborate to achieve the objectives of an engineering project and where Computer Aided Applications (CAx) and PLM applications are the technological enablers.

For the academic project, we have planned a two-semester design project that integrates several subjects (Fig. 2).

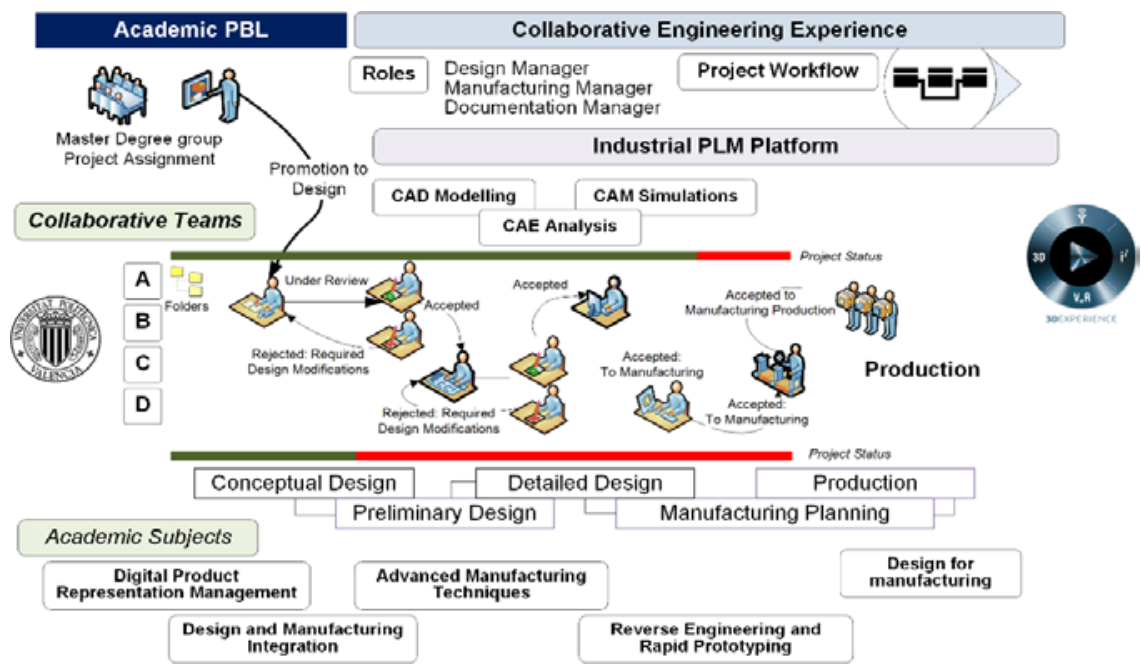

Fig. 2. CSCW Project Based Learning with PLM platform.

The academic subjects are mainly related with design and manufacturing skills and all of them belong to the specialization within the last year of a two-years Master Degree. Therefore, we have designed a project that, in some tasks, needs the technical knowledge and the tools or authoring applications for creating components.

The project has been structured in six main phases with simple tasks, milestones, deliverables and gates for going through the next phase.

After agreeing the structure of the project, it has been implemented in the PLM platform using the project management functionality (Fig. 3). 


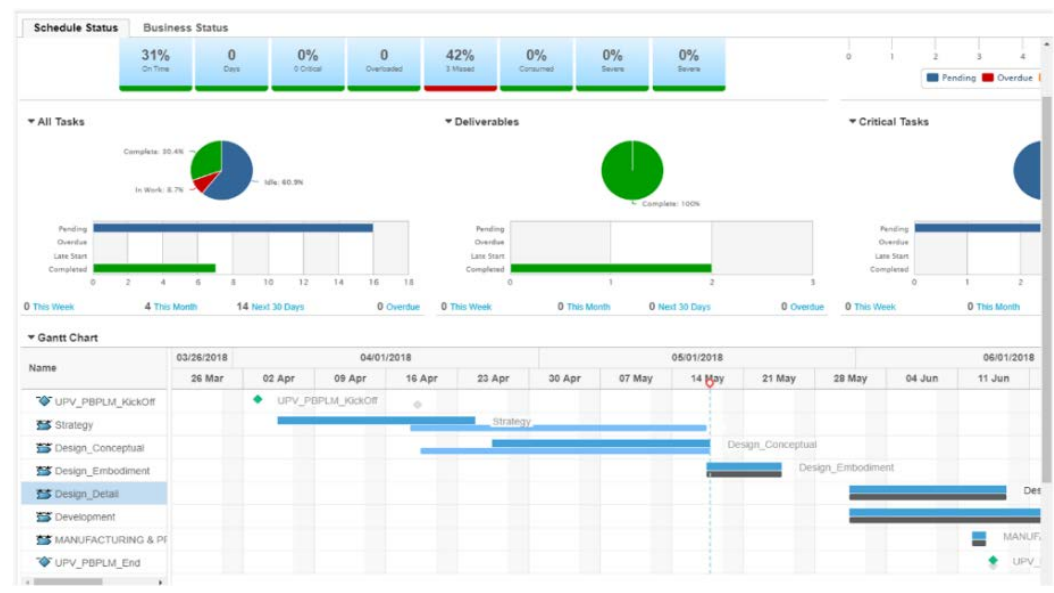

Fig. 3. Project structure used for the academic learning.

The characterization of a product design and manufacturing project template has helped to review the project progressions of each academic team.

\section{$4 \quad$ Experimental procedure}

The pilot project started at the beginning of the academic year with the objective of reproducing a real case with a PLM industrial tool. Although individual courses are focused on teaching fundamentals in design, CAD design and manufacturing, we created a learning environment of how to work in design and manufacturing engineering environments with CAD/CAE/CAM and PLM systems in a collaborative way.

The key element has been not only to design and to deploy several experiences with a CAx-PLM software framework but also to explore how to face commercial tools integrating technical knowledge from the academia perspective. It has included also the analysis of how to manage the learning process of advanced applications among all the previously proposed categories and functionalities. For this academic project, we have used the 3DEXPERIENCE platform from Dassault Systemes.

The software framework provides a wide range of apps for unstructured collaboration, structured collaboration, information intelligence, and engineering content creation and management. The students started the learning process by practicing through activities such as 3D modeling, 3D tolerance analysis, 2D drawings creation, component analysis and simulation, and material removal processes definition and simulation, which they will carry out collaboratively. In order to handle this advanced educational scenario, an action has been launched to create and share learning experiences promoting collaborative engineering education. 


\section{$5 \quad$ Results and Discussion}

Once the environment was arranged, the kickoff of the projects has been launched and all the collected information is being processed to enrich the academic training oriented to future engineers and new experiences. The project includes three parallel projects that collaborate and compete at the same time.

Although new platforms are based on the web with social interfaces, there are some new issues in these platforms. For example, how to integrate social apps with complex tools. Therefore, the first step was to create the learning interface and the training exercises repository. Abilities of viewing 3D parts is really important at least in engineering (Fig. 4)

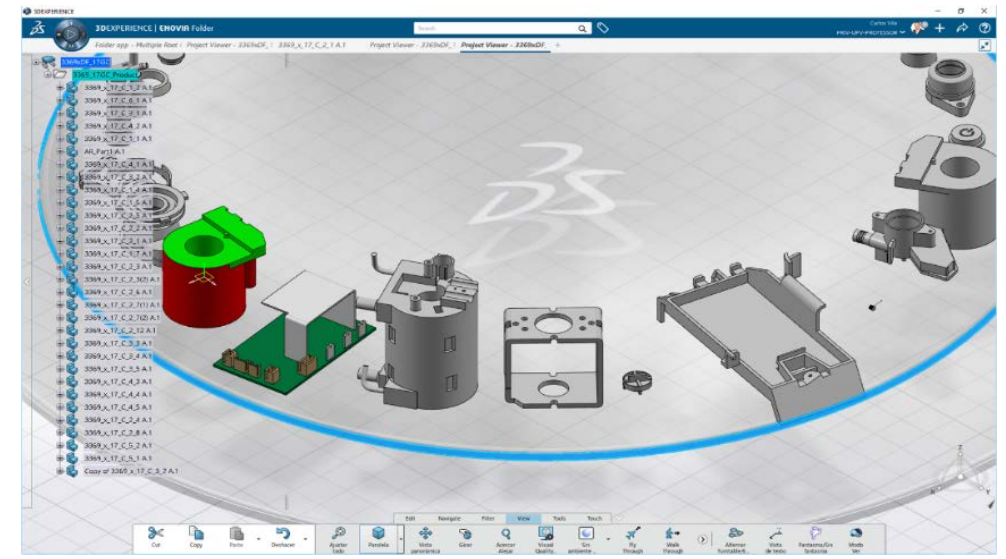

Fig. 4. PLM training workspace in 3DEXPERIENCE platform.

Then, we had to manage the parallel learning of PLM platform, particular CAx tools and social applications with regular technical content while achieving partial project milestones.

If we focus on the barriers, we have found that the first barrier to overcome is to commit with the project planning and the sequence of tasks. Students are used to work directly on the CAD tool without preparing the work. The learning curve of the apps at this level is not easy and the problem is to transmit the knowledge in short academic sessions. Another barrier is the complexity of the platform due to its completeness, it has many courseware materials for self-learning, but they last too many hours that is good for specific but goes against a fist approach to the lifecycle general vision.

We could say that the main barrier has been not the technical but the cultural change that the student has to achieve using the platform that allows showing what other colleagues are doing in real time, which has not been usual until now.

It is important to highlight that the execution had to overcome the difficulties in learning a new tool with many applications. Under the lecturer supervision, students have reviewed, designed and simulated the manufacturing process. 
Regarding to the evaluation of the skills, we can say that although it is difficult to get students to work in parallel on the web but once they are familiar with the new way of working results arise spontaneously. Because the platform is web based, instructor can review what they are doing online and has a general vision of all the engineering projects (Fig. 5). The evaluation of the acquired skills is done reviewing the quality of the results obtained from a dedicated application.

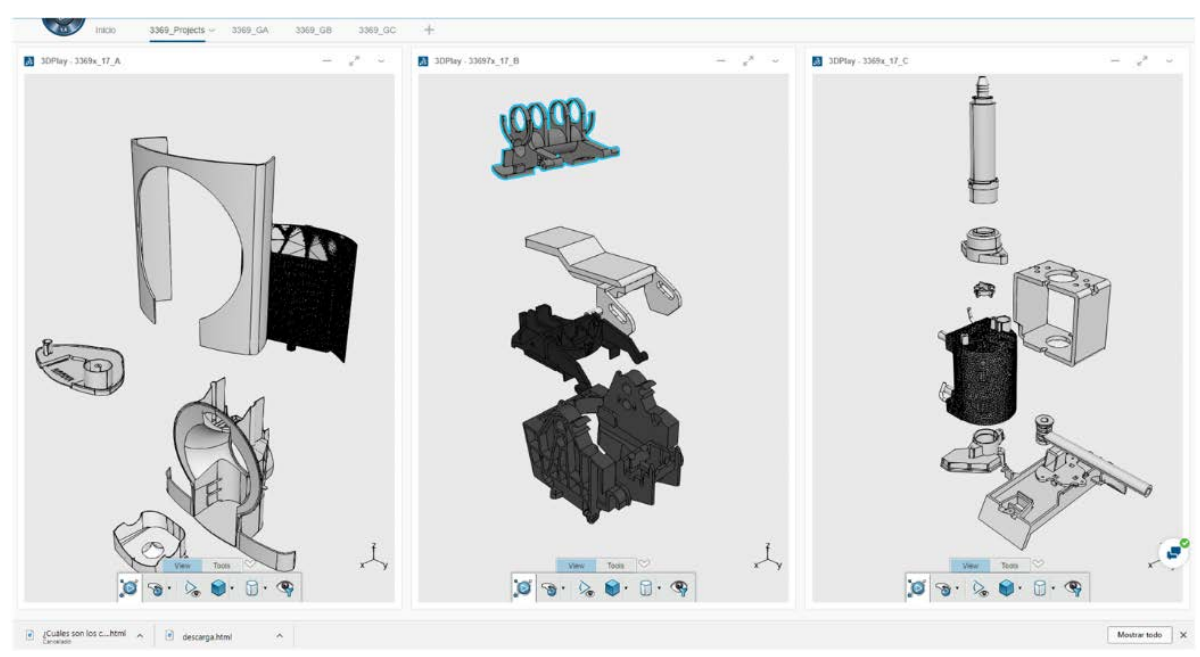

Fig. 5. PLM training 3DEXPERIENCE on the web partial results.

Concerning to the factual evaluation and measurement of the results these platforms record all the activities. Therefore, you cannot only review the quality of the project but also the participation of each member and content creation, which can be reflected in the final individual mark including skills evolution.

Another advantage is that all the CAx apps are integrated and there is a possibility of revision including from the tablets or smart phones similar to social networks. For the pilot we have used an example of designing a product doing reverse engineering. It is divided in projects for each subassembly and team and they share parts and restrictions through the platform. Therefore in this case study is complicated to compare since they are parts of a hole product and the only thing in this case we could compare was the different tasks and the fulfillment of times.

\section{Conclusions and Future Work}

Lessons learned from project based learning experiences have allowed us to identify different collaborative engineering skills problems that can be translated to company engineer's training. Firstly, the architecture, structure and templates of each learning project are different but there is a baseline that can be shared in each learning project. Secondly, the students output and feedback on from each project will help to correct 
the learning issues, since we have to control the learning if we want to succeed in this tools training.

Current practices have showed the need to define templates and collaboration procedures to make an appropriate and efficient use of the features and to accelerate the students' learning curve. This aspect is critical, especially where the available functionalities are extremely large and students are unable to identify which capabilities use and for what.

Concerning future works, we have to be able to define real projects in collaboration with industry. An initial step could be to define digital twin labs not only inside the university but also with other one to test the real distributed collaboration.

\section{$7 \quad$ Acknowledgements}

The authors would like to thanks to La Fondation Dassault Systèmes for its funding support and to Universitat Politècnica de València for its support to the project “Competences Development in Collaborative Engineering through Project Based Learning of Industrial Design and Development with PLM tools”.

\section{References}

1. C. Burchardt, "Education at University in Industry Context," IEE Int. Conf. Eng. Technol. Innov., 2015. DOI: 10.1109/ICE.2015.7438666.

2. S. C. Y. Lu, W. Elmaraghy, G. Schuh, and R. Wilhelm, "a Scientific Foundation of Collaborative Engineering,” CIRP Ann. - Manuf. Technol., vol. 56, no. 2, pp. 605-634, 2007.

3. L. Monplaisir and N. Singh, "Collaborative engineering for product design and development,” in Amer Scientific Pub, 2002. DOI: 10.1016/j.cirp.2007.10.010.

4. M. Grieves, Product Lifecycle Management: Driving the Next Generation of Lean Thinking. McGraw-Hill Education, 2005.

5. M. Hermann, T. Pentek, and B. Otto, "Design Principles for Industrie 4.0 Scenarios: A literature Review," 2016.

6. L. M. Gogan, A.-D. Popescu, and V. Duran, "Misunderstandings between Cross-cultural Members within Collaborative Engineering Teams," Procedia - Soc. Behav. Sci., vol. 109, pp. 370-374, 2014. DOI: 10.1016/j.sbspro.2013.12.474.

7. J. V Abellán, G. M. Bruscas, A. M. Estruch, and C. Vila, "Project-based collaborative engineering design and manufacturing learning with PLM tools," Lect. Notes Comput. Sci. (including Subser. Lect. Notes Artif. Intell. Lect. Notes Bioinformatics), 2009. DOI: 10.1007/978-3-642-04265-2_55.

8. C. Vila, J. V. Abellán-Nebot, A. M. Estruch, and H. R. Siller, "Collaborative product development experience in a senior Integrated manufacturing course,” Int. J. Eng. Educ., vol. 25, no. 5, 2009.

9. S. A. Rajala, "Beyond 2020: Preparing engineers for the future,” Proc. IEEE, vol. 100, no. SPL CONTENT, pp. 1376-1383, 2012. DOI: 10.1109/JPROC.2012.2190169.

10. J. C. Albiñana and C. Vila, "A framework for concurrent material and process selection during conceptual product design stages,” Mater. Des., vol. 41, pp. 433-446, 2012. DOI: 10.1080/00207543.2015.1110632. 